\title{
Los cuatro ministros de asuntos exteriores de Franco durante la Segunda Guerra Mundial
}

\author{
JAVIER TUSELL
}

A la hora de abordar la posición española ante la segunda guerra mundial ha sido bastante habitual la personalización de la misma en la figura de Franco. De acuerdo con esta interpretación resultaría que el Jefe del Estado habría guiado en exclusiva la política exterior durante este período y que lo cambios ministeriales producidos durante el mismo habrian sido el indicio de la elección de un rumbo diferente por parte suya. De acuerdo con ella, además, la función de los ministros habría sido tan sólo instrumental y el propósito de Franco habría sido único y siempre el mismo: el mantenimiento de la neutralidad española.

La verdad es, no obstante, muy diferente. Por supuesto de ninguna manera se puede decir que esa política única y esa voluntad neutralista existieran. La política española en torno a la guerra mundial dependió en un elevado grado de las circunstancias porque nunca España pudo condicionar los resultados de la contienda por sus propias fuerzas militares 0 por su potencia económica; tan sólo pudo influir en los acontecimientos a través de posición estratégica en el momento en que ya se habia producido la derrota francesa. Entonces no hubo nada parecido a neutralidad de la misma manera que no hubo una única política de acuerdo con los avatares de la guerra a partir del verano de 1940 sino una sucesión de matices.

Por otro lado la pretensión de que la política de Franco en torno a la guerra mundial fuera única e inamovible choca con lo que era su carácter y su estilo peculiar de gobierno. Franco podía partir de unas ideas generales respecto de los intereses españoles en torno al conflicto pero a lo que tendía era a adaptarlos a las circunstancias. El campo de la política exterior era, por otro lado, ajeno a su experiencia y a sus conocimientos con lo que nada tiene de extraño que el grado en que imprimió un determinado sesgo a la acción política fuera menor que en otros campos. De 
ahi deriva la importancia del papel que le corresponde a cada uno de los ministros de Asuntos Exteriores que tuvo durante la etapa bélica. Ellos se ocuparon del día a día de las relaciones con otros países pero, al menos en dos de los casos, impusieron además su propio sello a la política exterior española. Por eso tiene sentido referirse a sus características personales, a su ideario en torno a la política exterior y a su peculiar forma de regir el Ministerio que les fue encomendado.

\section{BEIGBEDER: UN PECULIAR AFRICANISTA}

La personalidad del coronel Juan Beigbeder ha podido ser considerada como una de las más enigmáticas de la política española durante el período de la segunda guerra mundial. La verdad es que hay elementos suficientes como para que se le pueda considerar así ${ }^{1}$. No era muy conocido en la vida pública española y tuvo un ascenso meteórico en ella pero la caída no lo fue menos y con ella se produjo su desaparición en el anonimato. Fue una de las personas cuyas cartas dirigidas a Franco resultan más sonrojantes por la capacidad para la adulación que muestran, pero, inmediatamente después de abandonar el poder, se dedicó a conspirar contra él, cosa que pocos compañeros de armas hicieron porque a lo más que llegaron muchos de ellos fue al ejercicio de la maledicencia. Habia sido germanófilo y su política como ministro de Asuntos Exteriores resultó por completo coincidente con los intereses del Eje, aunque sólo fuera por el momento en que le tocó tener la responsabilidad de la diplomacia española, pero ha quedado en la Historia española como un anglófilo por la postura que adoptó a partir el momento en que abandonó su cargo ministerial. En realidad no se puede decir que lo fuera propiamente: si congenió muy rápida y estrechamente con el embajador británico Samuel Hoare fue porque, cuando llegó éste a Madrid, ya estaba iniciándose su declive y en él encontró un aliado frente a Serrano al que, como tantos otros, acabó odiando. Finalmente para comprender que su personalidad haya resultado poco propicia a juicios taxativos y parezca inclasificable hay que tener en cuenta que el conocimiento de las fuentes diplomáticas de otros países nos permite constatar la extraordinaria duplicidad de sus manifestaciones ante los representantes extranjeros; de ella no acabarán de darse cuenta

1 Sobre Beigbeder hay tan sólo dos artículos de HALSTEAD, "Un africain méconnu..." y "A somewhat machevellian face..." Son escasas también las referencias en memorias de otros personajes pero véase Serrano, "Memorias", 266 y RidRuejo, "Casi unas memorias", 105 y HoARE, “Embajador», 51 y 77 . 
éstos por la sencilla razón de que lo corto de la permanencia de Beigbeder al frente del Ministerio lo impidió.

Afortunadamente disponemos de una fuente inédita para llegar a entender algo mejor la mentalidad de este curioso coronel: nada menos que unas memorias inéditas que tienen, sin embargo, el inconveniente de concluir en el momento del estallido de la guerra civil pero que están acompañadas de alguna documentación complementaria más, muy interesante para llegar a comprender algún aspecto de su gestión ministerial. En concreto parecen solventar la cuestión del intento español de obtener una ampliación de su protectorado en el Norte de Africa cuando, en el verano de 1940 , se produjo la derrota francesa.

Nacido en 1888, Beigbeder era, por tanto, cuatro años mayor que Franco. Ha sido muy habitual explicar la relación entre ambos por su mutua condición de africanistas pero es preciso matizar ésta porque de lo contrario no puede entenderse la personalidad de cada uno. Hay que tener en cuenta en primer lugar que Beigbeder era un militar «intelectual", por así denominarlo, de considerables lecturas y conocimientos, que se quejaba a menudo de la "anemia" cultural del Ejército. Pertenecía a un arma "técnica", como era la de Ingenieros, y fue diplomado de Estado Mayor. Su horizonte biográfico resulta mucho más cosmopolita que el de Franco pues entre 1926 y 1934 estuvo como agregado militar en varios países, entre ellos en Francia y Alemania. Su interés por otras cuestiones distintas de su propia dedicación profesional aparece en sus memorias cuando, por ejemplo, se describe a si mismo dedicándose a prospecciones arqueológicas en yacimientos romanos en Marruecos. Todo ello está situado en las antípodas de Franco, aunque se pueda pensar que la identidad la establece la común pertenencia a una familia de marinos que no pudo seguir esta trayectoria porque se lo vedaba la derrota del 98.

Claro está que puede reargüirse que ambos eran militares y tuvieron una experiencia africana que les marcó profundamente. Sin embargo lo cierto es que en este terreno las diferencias eran mayores que las semejanzas. Si hubiera escrito sus memorias Franco, por ejemplo, no hubiera descrito como "embrutecedora" y "mediocre" la vida de guarnición en provincias, como hizo Beigbeder, ni hubiera añadido que ser militar consistía en pertenecer a una "burocracia uniformada" encargada de ejercer funciones de policia y menos aún habría calificado a Weyler, una figura emblemática del Ejército español de entonces, de general «sanguinario, de prestigio nulo y de competencia inexistente".

Pero, sobre todo, la relación que tuvo Beigbeder con Marruecos fue muy diferente de la que caracterizó a Franco. Hubieran podido coincidir 
ambos en la crítica a la "ignorancia absoluta» - como decía el primeroque se tenía en la Península respecto de la política a llevar a cabo en Marruecos, a la falta de instrucciones a sus militares y al permanente deseo de liquidar el conflicto por el procedimiento de evitar las bajas propias y pactar con los indígenas. Sin embargo Beigbeder tenía una imagen mucho más nítida del modelo a seguir como alternativa: Francia que trataba a los españoles como uparientes pobres pero constituía un modelo a imitar". Eso no obsta para que durante la primera guerra mundial Beigbeder se reconociera, al mismo tiempo que la mayor parte de sus compañeros de armas, como germanófilo por contraposición a una Francia prepotente y despreciativa; en sus memorias llega a decir que, en el momento del estallido de la guerra, si Franco habia conseguido algunos contactos con los italianos para que le dieran ayuda, él logró los esenciales para que ésta viniera de Alemania. En el fondo Beigbeder tenía claro que España debía copiar el modelo de Ejército colonial de los países más avanzados; por eso también mencionó como modelo ideal a la Gran Bretaña. También hubiera sido inconcebible en Franco que escribiera de Berenguer, en tono laudatorio, que "parecía un general inglés", como hizo Beigbeder.

En especial la relación misma con Marruecos fue diferente en Franco y en Beigbeder. Franco profesaba pasión por su propia experiencia biográfica en el Ejército de Marruecos pero en realidad lo esencial en él no era un interés apasionado por esa región africana. Lo que le interesaba era ese género de guerra con respecto a la cual Beigbeder era más bien despreciativo porque, según aseguró en sus memorias con toda razón, se parecía más a la guerra de la Independencia que a la concluída en 1945. Beigbeder, en cambio, era un apasionado de Marruecos por sí mismo: lo describió, en esas páginas autobiográficas, como «hosco, impenetrable, singular y seductor'. Sus memorias revelan que en 1905 trató de marchar allí como instructor del ejército del Sultán. El sólo hecho de tramitar esta petición hubiera sido inconcebible en el caso de Franco y en el de Beigbeder tuvo como consecuencia una sanción. En los momentos finales de su vida en que escribió esas memorias ya pensaba en la posibilidad de que Marruecos se convirtiera en independiente y opinaba que debía hacer cuanto fuera necesario para no perder su personalidad ( Marruecos debe seguir siendo Marruecos»). Era quizá ese interés por lo marroquí lo que le dió unas peculiares características a Beigbeder. Franco era un militar coIonial mientras que Beigbeder tenía algo del viajero romántico de otros tiempos.

Convertido en Alto Comisario en Marruecos a partir de 1937, Beigbeder permaneció allí toda la guerra civil. Su fulgurante éxito político deriva, sin 
duda, del conocimiento que de él tenía el propio Franco (que debía pensar que un diplomático tenía sobre todo que saber idiomas, que él no dominaba), pero también del hecho de que Serrano Suñer y alguno de sus colaboradores más directos, como Dionisio Ridruejo, viera en él un buen organizador del Partido en Marruecos. Sin duda esto contribuyó de manera importante a su promoción en agosto de 1939 hasta el puesto ministerial, pero en ello como en el caso de otros militares (Varela, por ejemplo) hubo un malentendido sustancial en su nombramiento que sólo se despejó con el transcurso del tiempo. Parece indudable que Serrano le recomendó a Franco (o éste mismo tuvo la iniciativa) apoyarse en militares más jóvenes que los generales que le habian nombrado Caudillo y que, por tanto, tenían una relación de dependencia directa con respecto a su persona. De ellos, sin embargo, sólo dos fueron falangistas (Muñoz Grandes y Yagüe) $y$ todos sin excepción acabaron enfrentados con Serrano. Beigbeder mismo podia ser antiliberal pero tenía poco de fascista. Quienes le rodearon en el Ministerio (por ejemplo, Bárcenas, su subsecretario) eran diplomáticos de la vieja escuela, conservadores, católicos y monárquicos, lo que, como era habitual en la tradición española, no quería decir que fueran clericales sino regalistas. Como en el caso del ministro no se trataba de personas propicias a muchas aventuras: hubiera sido inconcebible que hubieran tenido algunas de las iniciativas de, por ejemplo, un Ciano o un Mussolini durante la guerra mundial.

La trayectoria biográfica de Beigbeder estuvo presente en su actuación como ministro. No cabe la menor duda de que su condición africanista derivó su concentración, mayor que en ningún otro ministro de Exteriores español durante la segunda guerra mundial, en la temática marroquí. Veremos cómo la ventaja que quiso obtener en el momento de la derrota francesa se refería a la ampliación del protectorado español pero, en realidad, antes del verano ya había demostrado de sobra sus preferencias en el momento de la elaboración del presupuesto de su Ministerio. Las cantidades atribuidas a Marruecos, que dependía de él, se multiplicaron muy considerablemente y de acuerdo con una nota que pasó por las manos de Franco resultaría que lo que se gastaba en él era una cifra muy superior a la que España empleaba en Obras Públicas o en Educación, por ejemplo ${ }^{2}$. En un aspecto, menos significativo, también es necesario indicar que el hecho de que España bordeara la ruptura con la Santa Sede durante su ministerio no es casual: era el mismo tipo de reacción que había tenido el almirante Magaz en Roma durante la guerra civil. Se trataba de

2 DIF, $11-1-45$. 
una actitud muy típica de los militares españoles sin necesidad de que fueran fascistas.

Con respecto al estilo de Beigbeder no es mucho lo que cabe decir. Se llevó bien con los miembros del cuerpo diplomático a los que concedió una libertad de maniobra considerable. A Franco le mantuvo puntualmente informado de toda su gestión: lo hizo de manera menos abrumadora que Jordana pero mucho más puntual que Serrano. Quizá lo más peculiar de su actividad como ministro fue la relación que mantuvo con el Caudillo que fue siempre de un extremado servilismo: las cartas que de él se conservan al Jefe del Estado se inician con un «Mi Caudillo" y concluyen con una despedida que sólo menciona dos palabras, "respeto y lealtad". Puede parecer que este aspecto de su forma de comportarse esté en contradicción con su cultura e inteligencia, pero no es así; en su caso es muy probable que se repita el de Lequerica. En el fondo ambos eran tan aduladores porque sabían hasta qué punto Franco aceptaba con complacencia que se empleara con él ese lenguaje. Otra cosa es que esa actitud sumisa y entusiasta respondiera a lo que realmente pensaban acerca de su superior. De todos los modos es posible que exista una diferencia entre ambos. Lequerica siempre fue más cínico mientras que en Beigbeder hubo una reacción colérica en cuanto dejó el Ministerio que le llevó a convertirse en conspirador. Verdad es que había sido humillado durante meses, cuando Serrano y no él dirigió en la práctica la política exterior, y que esa situación todavía empeoró cuando fue despedido de una forma mucho más denigrante todavía por el propio Franco. El despecho se veía multiplicado por la conciencia de la superioridad propia en muchos terrenos aunque antes se hubiera utilizado un lenguaje tan servil. En suma, en su reacción no hay nada de inesperado aunque tampoco nada en que pueda apreciarse un componente ideológico. Es muy posible que el Beigbeder posterior a 1940 fuera un hombre destruido psicológicamente de forma irreversible.

\section{SERRANO, EL HOMBRE DEL EJE}

La llegada al Ministerio de Asuntos Exteriores de Ramón Serrano Suñer en octubre de 1940 obliga a emitir un juicio global acerca de lo que significaba a estas alturas en la política exterior española. Eso, a su vez, impone previamente tratar de su significación política con carácter global aunque lo haremos evitando dar una extensión excesiva que vendría aconsejada por el propio carácter crucial que desempeñó en la vida pública española de estos años. 
Beigbeder ha podido ser un enigma para muchos de los que le conocieron, en el caso de Serrano Suñer el enigma no existe porque todos los que estuvieron cerca suyo tuvieron opiniones muy claras acerca de su persona. Lo más característico es, sin embargo, que estos juicios resultan por completo contradictorios, presentando al personaje con unas luces tan distintas que el historiador tiene la sensación de que se trata de individuos diferentes. Estrella fulgurante de la vida pública española mientras estuvo en el poder hasta el punto de dar la sensación de que en relevancia no distaba tanto de Franco y Serrano se vió beneficiado a continuación por haber tenido como colaboradores a algunos de los intelectuales más brillantes ( $y$ también más fascistas) de la España de los treinta. Eso - y su propia obsesión por la reconstrucción del pasado- explica que su fama historiográfica haya sido relativamente positiva. Tan sólo la publicación sistemática de la información diplomática de todos los paises y los trabajos de investigación monográfica aparecidos desde mediados de los setenta han cambiado esta situación en detrimento del ex-ministro.

Con respecto al propio carácter de Serrano el autor de estas líneas ya intentó en el pasado un estudio en paralelo entre las opiniones de dos personas que estuvieron cerca suyo durante el período de guerra civil ${ }^{3}$. La contraposición en los juicios resulta rotunda pero obedece a razones que no dejan de mostrar una cierta coincidencia. Dionisio Ridruejo le describe como un personaje traumatizado por el recuerdo de la guerra civil y en perpetua tensión moral como consecuencia, a la vez, de ella y de las responsabilidades políticas que asumía en este momento. El Conde de Rodezno nos lo presenta como un ser enfermizo y tortuoso y narra hasta qué punto resultaba insoportable para el resto de los ministros. Hasta aquí las coincidencias a pesar de la aparente distancia entre los calificativos empleados por los dos personajes.

Pero venían luego las diferencias y en este terreno no es posible asemejar las opiniones de los dos políticos citados porque sus perspectivas eran por completo distintas. Ridruejo fue un colaborador directo y un subordinado fiel de Serrano que debía tener hacia él el respeto que se muestra de forma habitual hacia quien tiene virtudes o capacidades de las que uno carece: en este caso se trataba del talento literario y de la condición de falangista de la primera hora. Rodezno significaba, por el contrario, una línea muy distinta de la fascistización y era un instalado en la política española nada menos que desde la época de la Restauración. En definitiva

3 TUSELL, "Franco en la guerra civil", 246-248 y 374-375. 
Ridruejo podia percibir y comprender la clave personal de la que nacia esa crispación de Serrano mientras que Rodezno sólo percibia las consecuencias en el trato con él. Poseido del convencimiento de que le correspondía poco menos que una tarea histórica Serrano demostró una absoluta carencia de don de gentes; por eso tendió a utilizar las personas como puros instrumentos. Se dejó adular hasta el infinito, encumbró y derribó sucesivamente a personas con valía o sin ella y maltrató sin necesidad tanto a quienes tenían capacidad para vengarse como a los inferiores. No supo ni siquiera tratar al propio Franco de quien derivaba todo el poder en la España vencedora en la guerra civil. Tenía la ventaja impagable de la proximidad familiar y eso le situaba en un nivel de influencia infinitamente superior al de cualquier posible contrincante. Como decía Saínz Rodríguez a fin de cuentas se acostaban con dos hermanas. Pero el error de Serrano fue considerar que tenía un poder autónomo propio como consecuencia de su identificación con la Falange y que éste tenía algo que hacer frente al de su cuñado. No dudó, cuando empeoraron sus relaciones con Franco, en practicar la maledicencia contra él. Antes, con ocasión del enfrentamiento circunstancial con su cuñado, no había tenido ningún reparo en utilizar un cambio de lenguaje que a una persona tan recelosa y megalómana como Franco debió resultarle difícil de aceptar. La documentación publicada por la Fundación Franco prueba, en efecto, que pasó del "Paco" a un "Mi querido general" que resulta sorprendente pues nadie cambió tanto en la forma de dirigirse al Caudillo. Rodezno, un adversario político, juzgaba que en Serrano la lealtad siempre se identificaba con el propio interés. Tan duro juicio quizá tenga una explicación más simple. Serrano se sabía superior en muchos aspectos a su cuñado cuyo carácter es posible que le acabara resultando muy difícil de soportar. Como quiera que sea no cabe la menor duda de que las relaciones entre ambos explican no pocas cosas en la política exterior de la guerra mundial.

Cuando estalló ésta ya Serrano Suñer aparecía como una especie de figura estelar en el firmamento de la política española. Era el definidor de los dogmas del Nuevo Estado porque de los generales no cabía esperarlo y los propios falangistas habían perdido a los principales dirigentes que podían desempeñar tal tarea. Como tal fue exaltado hasta unos límites que hoy nos pueden parecer inconcebibles por una prensa que él mismo controlaba. Cuando en agosto de 1939 cambió el gobierno de Franco quienes, entre los extranjeros, estaban mejor informados de los destinos de la política interna española - es decir, los italianos- no dudaron en asegurar que la política española estaba dominada no por una sino por dos personas $y$, en el fondo, juzgaban que para sus propósitos quizá resultara más importante Serrano que el propio Franco. 
La tarea que éste asumía, ya en agosto de 1939 tenía dos vertientes que eran complementarias. Si, por un lado, era el definidor de la nueva estructura política del régimen por otro lado le correspondía también encontrar un modelo a imitar y una política exterior que fuera su correlato. Como sabemos Serrano encontró lo uno y lo otro en la Italia de Mussolini. No es necesario demostrar ese paralelismo en la política interna pues bien claro aparece en todas las disposiciones que se tomaron con carácter paraconstitucional en la España de la posguerra. Lo que Serrano no tuvo en cuenta es que el fascismo era un movimiento político todo lo caótico que se quiera pero con peso específico propio mientras que la Falange tenía una importancia menor en la España de 1936 y no pasó de esa situación ni siquiera con la victoria, al menos en comparación con los militares. Además Mussolini había estado al frente del fascismo y Franco no de la Falange en la que el propio Serrano, aunque fuera mucho más capaz que cualesquiera de los camisas viejas, era, en definitiva, un advenedizo. Casi de seguro erró Ciano cuando afirmó a su suegro que Franco estaba "dominado" por la personalidad de Mussolini. Aunque tuviera agradecimiento hacia él (e incluso admiración) lo cierto es que aquel término parece por completo excesivo. En el caso de Serrano parece, sin embargo, más apropiado, pues en definitiva gran parte de su formación la había recibido en Italia, aunque sin duda también trataba de aparecer en el seno del régimen franquista como una especie de Ciano en el fascista, es decir fundamentando su influencia en lo personal o familiar.

Cuando Serrano visitó por vez primera Italia en 1939 aseguró que España estaba "por sentimiento y por razón" al lado del Eje. Esta afirmación es válida no sólo para él sino para casi la totalidad de la clase dirigente del franquismo de tal modo que el elemento diferencial parece tan sólo el énfasis puesto en la afirmación o en cada uno de sus términos. Eran muy pocos los dirigentes del régimen que pensaran en el mantenimiento de la neutralidad estricta en caso de conflicto. Eso es lo que explica que en el momento en que se produjo la derrota francesa no fuera un solo sector de la política española sino todos ellos los que pretendieron la entrada española en la guerra una vez prometidas las correspondientes contrapartidas.

Lo característico de Serrano fue el énfasis absoluto puesto en la frase citada. Siempre creyó que el destino de la política interna española y la posibilidad de cumplir las ansias imperiales del falangismo se jugaban en la guerra mundial al lado del Eje. Siempre, además, se presentó como el paladín de esta política ante alemanes e italianos, sobre todo ante estos últimos. Cuando, por ejemplo, aseguraba ante el embajador italiano que había tenido una conversación "dramática" con Franco para decantarlo a favor del Eje no hacia otra cosa que presentarse a sí mismo, por voluntad 
propia y sinceridad total, como el representante de su política en España. Una vez que Franco ( $y$ es posible que también él mismo) se dió cuenta de que lo que el Eje ofrecia era poco y las circunstancias de la vida española resultaban las menos propicias para entrar en una guerra aceptó permanecer al margen del conflicto pero tan sólo con carácter temporal: siempre, en efecto, dió la sensación de que aceptaba la no beligerancia como una situación provisional que acabaría por superarse con el transcurso del tiempo en cuanto cambiaran las circunstancias. Todavía daba una impresión peor a los neutrales o a los aliados. Del binomio razón y sentimiento que ya ha sido citado a menudo parecía guiarse más por el segundo que por la primera. El embajador portugués decía, por ello, que ofrecia la mezcla de excitación, megalomanía, gusto por los gestos vistosos, dureza y falta de escrúpulos de los dirigentes de los países del Eje y que era ello precisamente lo que podia conducir a España a una catástrofe ${ }^{4}$. Razón tenía en temerle porque con relación a Portugal puede decirse que existió una diferencia al menos de matiz entre Serrano y Franco: el primero extendía al vecino país el imperialismo de la Falange, cosa que era menos apreciable en el segundo.

Merece la pena tener en cuenta también lo que asegura el embajador luso respecto del estilo político de Serrano. Por supuesto tuvo Serrano una marcada tendencia a tener relaciones conflictivas con no pocos embajadores y no sólo con los aliados (Hoare o Weddell) sino también con los neutrales. Teotonio Pereira dice haber sentido en una ocasión la tentación de partirle la cara. Incluso es posible que las malas relaciones con Ribentropp se debieran no sólo a su voluntad de no ceder ante él sino al carácter de Serrano. Fue, además, absorbente hasta el extremo. No dudaba en asegurar ante quien quisiera oirle que él era el único ministro español con categoría como para tener una presencia presentable más allá de las fronteras propias ${ }^{5}$. Tampoco tuvo el menor reparo en tratar a embajadores y embajadas españoles de acuerdo con sus intereses personales. Al general Espinosa de los Monteros no le había nombrado él embajador en Alemania y procuró no tenerlo en cuenta en absoluto; la embajada en Roma, poblada por falangistas adictos a su persona, permaneció vacante durante mucho tiempo a la espera de que él decidiera o no ocuparla. Nada más llegar al puesto de Ministro de Exteriores embistió contra la carrera diplomática en parte por razones ideológicas (quería que predominaran en la política exterior criterios políticos y no de escalafón)

PTP/OS, II-2, 121.

PTP/OS, III, 118. 
pero también porque no se trataba de adictos suyos. El problema que tuvo es carecer en el seno de la Falange de apoyos personales suficientes como para modificar de forma significativa la acción diplomática, pero potenció la Delegación Nacional del Servicio Exterior y hubo un momento en que quien la desempeñaba, Ximénez de Sandoval, tuvo en sus manos una responsabilidad inmensa, como jefe de Gabinete del Ministro, consejero de la Hispanidad y responsable de la prensa en materia de política exterior. Pero Ximénez de Sandoval acabó causándole graves problemas políticos y en la etapa final de su ministerio tuvo de nuevo que apoyarse en los diplomáticos tradicionales que nunca habían dejado de desempeñar un papel decisivo porque no había con quienes sustituirlos. De sus dos subsecretarios sucesivos, Peche y Pan de Soraluce, se pudo decir que eran más bien aliadófilos; el primero no dudó a veces en criticar los modos diplomáticos de su superior e incluso los contenidos de su acción.

Es preciso, en fin, hacer mención también a un último aspecto de la ejecutoria de Serrano Suñer como Ministro de Asuntos Exteriores. Las opiniones de la totalidad de los embajadores extranjeros sobre su manera de llevar el Ministerio son coincidentes en afirmar que muy a menudo faltaba de su despacho y que, en general, su dedicación no pasaba de irregular: estaba hasta cuatro o cinco dias sin aparecer por él y tardaba mucho tiempo en cumplir con sus obligaciones a la hora de recibir visitas (nueve semanas tardó en recibir al representante húngaro). La principal razón de ello puede estar en el hecho de la pluralidad de sus dedicaciones políticas: no sólo siguió desempeñando en la práctica el Ministerio de la Gobernación durante muchos meses sino que además presidía la Junta política y, según el embajador portugués, muy a menudo escribía parte de los editoriales de "Arriba" ${ }^{6}$. Si todas estas dedicaciones eran normales $y$ explicables to era menos el hecho de que con mucha frecuencia empleara largos fines de semana en cacerías que el propio embajador italiano le reprochaba y que contribuyeron de forma importante a desordenar su trabajo burocrático. Este, por otro lado, dependió también estrechamente de sus relaciones con el resto de la clase política del régimen e incluso de sus cambiantes vínculos de amistad y familiaridad con Franco. Las conversaciones que tuvo con el embajador italiano prueban que en no pocas ocasiones la batalla política interna era para él tan absorbente que en realidad no podia hacer otra cosa que dedicarse a ella. Hubo ocasiones, además en que, para demostrar su enojo y su fuerza en el entorno de Franco, ni siquiera asistía al Consejo de Ministros. Un último aspecto, en fin, a la

6 PTP/OS, II-2, 460. 
hora de referirse a la forma de despachar con Franco en materias de su competencia. Llama la atención el hecho de que en la época en que Serrano Suñer estuvo al frente del Ministerio los informes de embajadores españoles en el extranjero $u$ otras informaciones de interés apenas llegaran a Franco como se demuestra por el hecho de que no figuran en Presidencia de Gobierno ni tampoco han sido publicados en los documentos inéditos de la Fundación Franco. Esto índica que Serrano, como cabía esperar de él, llevó la política exterior de forma muy personalista, con cierta autonomía del Caudillo, al que no siempre le informó por completo; aparte de ello resultaba bastante desordenada y, por supuesto, con graves inconvenientes para lo que luego ha sido la tarea del historiador. Gran parte de la documentación administrativa que tuvo su origen en su etapa ministerial y por supuesto la más importante quedó en sus manos en el momento en que dejó el ministerio.

Las dificultades puestas al historiador del futuro en el cumplimiento de su misión no han impedido en absoluto que la trayectoria ministerial y la significación política de Serrano hayan podido ser reconstruidas a pesar de que sus repetidos libros de memorias traten de inventar el pasado de un modo que no tiene fundamento alguno aunque testimonie la evolución ideológica del cuñado de Franco. Importa señalar que no sólo mantuvo su posición hasta el final mismo de la guerra mundial sino que en 1944 no tuvo inconveniente en ofrecerse no ya a aquel con quien había tenido un contacto más estrecho y amistoso (Mussolini), sino al propio Himmler ${ }^{7}$. Esto, que ratifica la posición que mantuvo durante la segunda guerra mundial, prueba que su evolución no se produjo sino concluida ésta y que, al menos, fue fiel a quienes habian sido los suyos casi hasta el final, lo que no puede decirse de tantos que habían colaborado en la fascistización del régimen.

Al margen de esta evolución posterior podemos considerar cuál era la postura de los beligerantes respecto del panorama de la política exterior española en torno al mes de octubre de 1942 cuando ya se aproximaba, la fecha del desembarco aliado en las costas norteafricanas. Esto nos permitiria completar el juicio acerca del personaje. Quienes sin duda tuvieron motivos para estar descontentos fueron los italianos y no sólo por la desaparición del escenario político de quien había sido un hombre en la política española sino también porque para ellos España era una carta que consideraban como propia y las dificultades crecientes en el terreno militar hacian pensar que pronto sería necesario utilizarla. Ahora las circunstancias

\footnotetext{
Carta de febrero en ADAP, E, VIII, 25-26.
} 
les hacian pensar que Serrano no era una persona en que debieran haber confiado tanto. Cuando el embajador italiano se entrevistó con él, ya a mediados de octubre, le encontró muy indignado contra Franco y herido por la rapidez con la que su poder político se había desvanecido. Pero esto último era tan evidente e irreversible que nada podian hacer los italianos para evitarlo. Ellos mismos habian sido testigos del carácter sectario del cuñado de Franco y de su maledicencia contra el Jefe del Estado. Las condolencias de Ciano tardaron bastante en llegar sin que hagan pensar en ningún momento en la posibilidad de que se pensara por los dirigentes fascistas que Serrano podia recuperar su poder. Incluso los italianos prefirieron que el destituido no apareciera como embajador español en Italia porque ello hubiera convertido su sede, al decir de Ciano, en un "nido de chismorreos». Las relaciones entre los dos países aparentemente no experimentaron novedad alguna permaneciendo presididas por muestras de cordialidad semejantes a las del pasado. Sin embargo ya en octubre, cuando los británicos habian comenzado su contraofensiva en el Norte de Africa, surgieron algunos incidentes inimaginables en el pasado. España protestó por dos veces ante Italia con motivo, en primer lugar, de la atribución que en la prensa de este último pais se había hecho del descubrimiento de América como empresa propia y con ocasión de una violación del espacio aéreo español durante un bombardeo de Gibraltar. Ambas cosas resultaban inimaginables cuando Serrano era ministro de Asuntos Exteriores. Se entiende, por tanto, que los italianos reclamaran un pronto nombramiento de embajador español. Sin embargo el que obtuvieron, Fernández Cuesta, aunque fuera falangista, no era persona con poder político efectivo ni tenía capacidad de iniciativa como para conseguir por sí mismo un acercamiento entre los dos países. Los alemanes, por su parte, confirmaron con lo sucedido la oportunidad de su decisión de no inmiscuirse en la política española, tan sujeta a vajvenes. A fin de cuentas Serrano a estas alturas ya era visto como un personaje en exceso celoso de su propio poder y, al mismo tiempo, poco simpático a Ribbentrop; además, habían visto desaparecer del panorama a una persona como Varela al que reputaban como un peligroso anglófilo. No querían la restauración de la Monarquía pero ésta no les parecía en absoluto cercana y en Jordana creían ver una persona de trabajo más asiduo y cuidadoso que Serrano. Además sabian que tenian partidarios en el seno de la Administración española. A comienzos de octubre todavía el embajador español en Berlín, Mayalde, un colaborador estrecho de Serrano que no tardaría en dimitir, planteaba a Madrid la necesidad de concretar las peticiones españolas a Alemania porque en cuanto ésta llegara al Cáucaso volvería a solicitar su entrada en la guerra. El propio 
Jordana, ya en septiembre, pidió armas a los alemanes con un propósito que era defensivo de la neutralidad propia pero que los alemanes podían entender con un deseo de mantener relaciones estrechas. En octubre mismo, sin embargo, hubo ya una protesta por la actividad de submarinos alemanes contra buques españoles ${ }^{8}$.

La actitud de los aliados fue esperanzada entre otros motivos porque su punto de partida, durante la etapa del ministerio de Serrano, era muy negativa. Hayes, el embajador norteamericano, se sorprendió favorablemente por la desaparición de falangistas uniformados del Ministerio de Exteriores e inmediatamente percibió un mejor y más fácil trato con sus autoridades. Muy pronto pensó que el cambio significaba «la sustitución de un mezquino, intrigante y muy escurridizo político, acosado por sus problemas de úlcera estomacal y sus ilusiones de grandeza, por un caballero que pertenece a la nobleza y al Ejército y que es honesto, digno de confianza, gran trabajador y dotado de buena salud y sentido del humor». Pero no se trataba tan sólo de eso: el embajador llegó muy pronto a la conclusión de que se trataba del reemplazo de un militante del Eje por otro ante todo proespañol y luego más simpatizante de los aliados que del Eje. La mejora en el comportamiento de la prensa y en las perspectivas comerciales parecían abrir una nueva etapa en las relaciones entre ambos países. En cuanto a los británicos hay que tener en cuenta que habian estado, estaban y seguirian estando en estrecho contacto con la Embajada de Portugal que fue la que demostró un mayor entusiasmo por el cambio acontecido en España por los motivos que ya han sido expuestos. A través de ella la Gran Bretaña consiguió, sin duda, durante toda la guerra mundial multiplicar de forma significativa su influencia en España. Hoare permaneció en Londres durante las primeras semanas posteriores al cambio gubernamental español para recibir instrucciones respecto del inminente desembarco en el Norte de Africa pero cuando volvió hizo un rápido diagnóstico de la situación del que llama la atención el durísimo juicio que hizo de Serrano directamente proporcional a lo mal que éste se lo había hecho pasar en el pasado. Lo comparó, en efecto, con Ribbentrop y Ciano, una trinidad de ministros totalitarios caracterizados, según él, por la vanidad y la perfidia, la ostentación y los celos, el cinismo y la petulancia. Según el embajador portugués, que le conocía mejor, era una persona que tenía gran encanto personal pero el británico no había conocido este aspecto de su personalidad; por el contrario le acusó de crueldad y dureza de carácter. Su trabajo burocrático en el

8 Tusell-García, “Franco y Mussolini", 173-176; Jordana-Lequio, 8-X-1942, AMAE leg. 2.300/7; Mayaide 7-X-1942 y Jordana 8-IX-1942, AMAE leg. 1.370/7; AMAE leg. 2.300/2. 
Ministerio había estado perjudicado por una mezcla de malhumor, absentismo y falta de cortesía elemental con respecto al Cuerpo Diplomático. Al resto de los ministros Serrano los despreciaba porque en realidad no pensaba más que en sí mismo. Sus viajes a Alemania e Italia tenían como único motivo darse importancia y no firmar pactos. Su egoísmo radical se habia podido apreciar sobre todo en el abandono de sus amigos hasta tal punto que en el momento presente no le quedaba ni tan siquiera uno. Había hecho todo lo posible para provocar una ruptura entre España y Gran Bretaña y si, en los últimos meses, había cambiado algo no se debía a una modificación en su forma de pensar sino a que el viento soplaba en contra de Alemania. A su sucesor no podía de momento juzgarlo pero sí, en cambio, pensaba que era prudente y por ello evitaría una transición brusca en un alejamiento del Eje. Cuando le conoció llegó a la conclusión de que podía tener una apariencia poco brillante, pero merecía confianza porque era sincero, patriota y honesto ${ }^{9}$.

En definitiva una vez pasadas unas semanas desde el cambio gubernamental había ya indicios suficientes en España de un cambio en la política exterior. Sin embargo los aliados estaban más confiados y los países del Eje no habían sido decepcionados por completo. El desembarco en el Norte de Africa contribuiría a un cambio sustancial de perspectiva.

\section{JORDANA, UN NEUTRALISTA A PESAR DE LAS CIRCUNSTANCIAS}

Después de la narración precedente pocas dudas podrán quedar acerca de que la crisis política que se produjo en España a fines del verano de 1942 no tuvo en realidad un origen que pueda remitir del conflicto mundial sino que estuvo motivada, de forma exclusiva, por la evolución de la política interna. La misma duda de Franco acerca de la cartera que debía ocupar Jordana testimonia que no tenía nada previsto un cambio en la política exterior a seguir. Quizá preferia un mayor grado de prudencia que otras etapas anteriores pero, a fin de cuentas, el propio Serrano en la última etapa de su gestión habia experimentado un cambio en este sentido.

Ahora bien si por un lado Franco no había previsto un cambio en la posición española ante el conflicto, Jordana acudia a su responsabilidad

HAyES, «Misión» 71-73, Frus, 1942, III, 295-298; Pereira-Jordana, 27-X-1942, AMAE leg 1.370/7, Hoare, 15-X-1942, FO 371/31. 238; HOARE, "Misión», 191-196. 
con un bagaje personal que en ningún caso cabe desdeñar y que sirve para explicar su gestión gubernamental en este período. Vale incluso para titular el presente capítulo puesto que, como veremos, aunque los acontecimientos bélicos jugaran un papel decisivo en la determinación de la posición española ante el conflicto mundial antes de que se produjera alguna de singular importancia ya había quedado definido un programa de política exterior.

Nacido en 1876 Francisco Gómez Jordana era un militar que pertenecía a una generación anterior a la de Franco: este nació el año en que el primer ingresó en la Academia (1892). Este hecho explica que su actitud ante él no fuera la del generalato joven, fácilmente identificado con el Caudillo, aunque tampoco fue la de los otros militares, de su generación o de otras posteriores, que tendieron a enfrentarse con él. Durante su carrera militar Jordana participó en la guerra de Cuba y después de ella tuvo un elevado número de destinos de carácter docente o en el Estado Mayor. Participó también en la guerra de Marruecos en donde logró ascensos por méritos de guerra hasta llegar al generalato. No participó en la organización del golpe de Estado de septiembre de 1923 pero fue vocal de su Directorio Militar por designación de Primo de Rivera (como se sabe éste repartió las vocalías eligiendo un general por cada región militar). Durante el período dictatorial sus responsabilidades se refirieron sobre todo a materias relativas a Marruecos. Participó en la preparación política y militar del desembarco de Alhucemas como consecuencia del cual recibió el titulo condal de Alfonso XIII. En relación con la cuestión marroquí adquirió experiencia diplomática participando en la Conferencia de Madrid en 1925 y la de París en 1926. En 1928 ascendió a Teniente General y fue nombrado Alto Comisario español en Marruecos, puesto que ya habia ocupado su padre entre 1915 y 1918.

Desempeñaba ese cargo cuando se produjo el advenimiento de la República. Inhabilitado con carácter perpetuo como consecuencia de la actuación de la Comisión de Responsabilidades, no participó, sin embargo, en las conspiraciones antirrepublicanas y la guerra le sorprendió en plenas vacaciones en San Rafael (Segovia). Se adhirió a la sublevación y desempeñó ante el bando de Franco un cargo al principio de escasa significación al frente del Alto Tribunal de Justicia Militar. Al morir Mola y pasar el general Dávila a sustituirle ocupó la Presidencia de la Junta Técnica de Estado a la que le correspondia la función administrativa de la retaguardia. Su significación política creció cuando Franco nombró su primer Gobierno, al ocupar la Vicepresidencia y el Ministerio de Asuntos Exteriores. Aparte de coordinar la labor de este primer aparato estatal del régimen, en función del primer cargo, representó un intento inicial para la 
normalización diplomática de la España de Franco con el exterior. A este respecto es preciso recordar su preferencia por el acercamiento con los sectores conservadores y católicos de paises como Francia y Gran Bretaña más que con los fascistas y su política de neutralidad en octubre de 1938 con ocasión del conflicto europeo que concluyó con la conferencia de Munich. No podía, sin embargo, reputársele de anglófilo aunque sí de muy poco proclive al género de fascistización que trataba de llevar a cabo Serrano. La victoria de éste en agosto de 1939 le marginó a la Presidencia del Consejo de Estado. Disconforme con la política seguida en el momento del ápice fascista tampoco se significó por la oposición a ella sino por el apartamiento; por eso a su nombramiento no cabe atribuirle el carácter de decisión tan clara en el terreno político.

Es difícil imaginar una más radical antítesis, en lo personal y en lo político, entre Jordana y Serrano. Si el segundo era un joven fascistizado, crispado por el recuerdo bélico, de ambición política exaltada y no tanta dedicación burocrática, proclive tanto al personalismo como a las filias y a las fobias y casi siempre interesado en dar una interpretación partidista a la diplomacia, el primero era un conservador clásico, monárquico y católi$\mathrm{co}$, tan poco interesado en la política como para practicar periódicamente la dimisión, cuando veía que no se seguia la política que sugería, de apariencia nada brillante e incluso prosaica, ordenado, trabajador, metódico y dotado de una experiencia diplomática previa. Por supuesto estos dos estilos vitales no tardaron en reflejarse en la gestión ministerial.

El cambio de un Ministro de Asuntos Exteriores a otro suponia una mayor tendencia hacia la neutralidad, pero se siente la tentación de decir que, antes incluso que eso, fue una especie de garantía al Ejército de que una responsabilidad tan fundamental como la de Ministro de Asuntos Exteriores en una circunstancia tan difícil como la que vivía el mundo no podía estar en manos de quien no lo era. En cuanto a la significación política de Jordana hay que recalcar que tenia del puesto que ocupaba la visión de un destino puramente militar. Su condición de monárquico era más que nada sentimental y su escasa simpatia por la Falange parecía biológica, más que producto del antifascismo. Cuando en junio de $1944 \mathrm{el} \mathrm{em-}$ bajador británico Hoare le sugirió que él podía ser el Presidente del Consejo en un gobierno monárquico se sintió desasosegado no sólo porque la noticia le podía llegar a Franco sino porque estaba muy lejos de pensar que ese debiera ser su papel, que él consideraba como por completo alejado de lo estrictamente político. En consecuencia escribió a Hoare unas líneas advirtiéndole que lo sucedido podia ser interpretado como una intromisión en la política interna española, que él no podia ni tan siquiera dar por oídas las sugerencias del británico y que éstas no podían 
ser más contraproducentes incluso para la misma Restauración de la Monarquía ${ }^{10}$.

Sobre Jordana ha pesado una mala fama historiográfica de la que es culpable, en gran medida, el hecho de que los principales memorialistas de la época hayan sido falangistas. Sin embargo la principal de las acusaciones implícitas que contra él se esgrimen sencillamente no se sostiene. Jordana no fue una simple marioneta de Franco. Lo cierto es casi todo lo contrario: influyó mucho más él en Franco que viceversa. Tenía una idea precisa de cuál debía ser la política española en ese momento y bajo ese régimen; no dudó en llevarla a la práctica en la medida en que pudo y no pocas veces actuó con total independencia y libertad de criterio. Como veremos a menudo tuvo sus enfrentamientos con Franco y no dudó en dimitir si eran graves. Fue un subordinado leal y fiel pero también tenaz en sus planteamientos y actitudes. Debió ser consciente de la susceptibilidad y la vagorosidad de Franco y por eso le bombardeó literalmente con sus escritos, lo que, con el paso del tiempo, ha resultado tener una gran utilidad para el historiador porque nos ha dejado rastros inapreciables de la política por él seguida. Asi se prueba por la abundancia de los existentes en Presidencia de Gobierno y el Ministerio de Asuntos Exteriores y los que luego han sido publicados en las colecciones documentales editadas por la Fundación Franco. En eso también la tendencia al secretismo y al personalismo de Serrano establece una diferencia fundamental con él. Por otro lado Jordana no dudó en ofrecer sus opiniones, incluso cuando no coincidian, con las de Franco; a diferencia de Serrano ni siquiera con aquellos representantes extranjeros con los que tenía mayor amistad hizo la menor crítica a Franco, mientras que este fue el caso del cuñado en su fase final.

Quizá el cambio que antes se apreció entre los dos ministros fue el relativo al método de trabajo. De manera muy rápida Jordana estableció la cordialidad personal con los embajadores, concentró la totalidad de la responsabilidad en política exterior en sus manos y estableció un sistema de correspondencia periódica con los embajadores españoles por todo el mundo. Su equipo en el Ministerio estuvo compuesto por diplomáticos profesionales de amplia experiencia que podían haber desempeñado un papel semejante en el reinado de Alfonso XIII y que no tenían vínculo personal ni político con él aunque los hubiera conocido durante su primera

10 AMAE leg. 1.372/22. Como cabia esperar la reacción de Franco, que se enteró del incidente de labios del propio Jordana, fue indignada, no sólo por nacionalismo sino porque afectaba a su poder político. Asi lo señala el diario de Jordana. 
etapa ministerial. El subsecretario siguió siendo Pan de Soraluce, que ya lo era en la época de Serrano cuando éste decidió reconciliarse con la profesión diplomática. Doussinague desempeñó una Dirección general de competencias extensísimas, casi de Secretaría de Estado en lo que sería el lenguaje administrativo actual, pues abarcaba las secciones regionales de Europa, Asia y Ultramar y las competencias en materias culturales. Frecuente redactor de textos de planificación puede existir la tertación de atribuirle más trascendencia de la que realmente tuvo por el hecho de que parece haber tenido buen acceso a El Pardo y por el libro que escribió con posterioridad a la guerra mundial respecto de la política exterior de esta época. En realidad algunos de los embajadores tuvieron un papel más importante que el suyo. Conservó a Alba en Londres y a Lequerica en Vichy, pero envió a Bárcenas, que habia sido su subsecretario en 1938, al Vaticano mostrando así la importancia que atribuía a este puesto. En Roma puso a un falangista manejable como Fernández Cuesta, lo que debió ser cruel para un Serrano que había considerado el puesto prácticamente como propio y que le consideraba su enemigo. En el fondo, al trasladarle desde Brasil lo que hacia era quitar a Falange su condición de columna del Eje en Hispanoamérica. A Berlín envió a Vidal y Saura, otro diplomático profesional que había trabajado con él durante la guerra civil. Era el primero de estas características que llegaba desde España a la capital del Reich ${ }^{11}$.

Un rasgo muy caracteristico de Jordana que, en cambio, a veces estuvo ausente en la acción de Serrano y también de los discursos de Franco fue la prudencia. La verdad es que nadie atribuyó una significación especialísima a su nombramiento; tan sólo los diarios portugueses lo elogiaron, quizá porque con este gobierno tenía una sintonía especial. "Arriba" presentó su nombramiento como un simple "relevo de guardia» indicando que el gobierno era el mismo porque lo presidia idéntica persona. Tanto la prensa británica como la alemana coincidieron en que la crisis era una reafirmación de Franco; la primera estuvo irónica con Serrano pero también la segunda le consideró un fracasado. A pesar de todo ello el mero hecho del desplazamiento de Serrano era susceptible de interpretaciones peligrosas y Jordana se apresuró a neutralizarlas. Lo hizo principalmente con los italianos que habian constituido el más conspicuo apoyo de la política serranista. Al representante diplomático italiano le ratificó que la política exterior española era la misma porque la señalaba el Caudillo y le prometió que su voluntad de satisfacer a Italia sería «por lo menos igual» a la de

11 PTP/OS, III, 222. 
su antecesor. En los primeros dias de su gestión algunas de las acciones encubiertas de carácter militar que los italianos realizaban desde España recibieron idéntico grado de protección que en la época anterior ${ }^{12}$. Pero las cosas cambiaron muy pronto. En realidad por lo que sabemos todo hace pensar que Jordana tenía una idea muy clara de que los aliados iban a ganar la guerra y de que España debía ser neutral. Sin embargo la propia prudencia con que actuó, tan característica suya, le condujo a optar por demostrar con los hechos cuál era su política pero no multiplicar las declaraciones acerca del rumbo que debiera seguir.

\section{LEQUERICA: REHACERSE UNA VIRGINIDAD}

La muerte del general Jordana, en agosto de 1944, no significó, por sí misma, un radical cambio de política pero muy pronto indicó un giro tendencial importante; algo parecido se puede decir del momento en que llegó al gobierno en septiembre de 1942. El acontecimiento fue inesperado en un momento en que, por recrudecerse las presiones de los aliados sobre España y por la aparente incapacidad del Gobierno español para cumplir los compromisos que él mismo se había señalado respecto del comercio del wolframio, una vez más el Ministro de Asuntos Exteriores parecía muy poco deseoso de mantenerse en su puesto. A fines de junio escribió en su diario acerca del hartazgo que sentia ante la «labor oscura, agria, antipática" que le tocaba desempeñar en la que, además, "cuando se crean los conflictos por los demás y yo los resuelvo todos menos yo han hecho el milagro". Si esto era cierto no lo era menos que sus mayores problemas derivaban de la rémora de una Administración y una clase politica germanófila que se convencía demasiado tarde y con demasiado esfuerzo de que el rumbo bélico iba en una dirección muy distinta de la que deseaba. Jordana, por talante y pensamiento, fue siempre neutralista: le inducian a ello tanto su condición de monárquico y conservador, lejano del fascismo, como su apreciación de las circunstancias bélicas las cuáles le hicieron pensar desde muy pronto en la victoria aliada. Frente a aquel género de ministros de Franco que tuvo una politica propia y sin duda en política exterior muy diferente habría sido la evolución de la posición española de no haber sido por él. Eso, sin embargo, no implica que llevara una política personal y propia: no tenía ambición política a pesar de que había medios monárquicos en los que se pensaba en él para desempeñar

12 Reacciones de la prensa en Aj; TuSELL-Garcia, “Franco y Mussolini", 171-173. 
un papel de primera importancia en un gobierno de esta significación. Su papel esencial consistió en empujar, con suavidad y algunos periódicos retrocesos, pero de forma inequivoca en favor de la politica exterior en la que creía: tomó en sus manos una España claramente proclive al Eje, de la que se pensaba que en cualquier momento podía intervenir en la guerra a favor de él y dejó un país que no sólo era neutral sino que tendía incluso a decantarse hacia la benevolencia frente a los aliados. Lo hizo, además, tras improbas jornadas de trabajo, con lealtad hacia Franco al que le mantuvo sin duda mucho más informado que Serrano. Otra cosa es que el Jefe del Estado supiera agradecer actitudes como ésa.

La muerte de Jordana se produjo como consecuencia de un accidente de caza que tuvo lugar el 23 de julio. Muy aficionado a ella el ministro daba cuenta periódicamente en su diario del número y calidad de piezas logradas. Ese día se golpeó al disparar contra un conejo. Los médicos no dieron importancia a la herida que se causó en la cabeza pero el golpe lateral le llevaría a la tumba cuando estaba ya en San Sebastián desempeñando el llamado ministerio de jornada, a comienzos de agosto.

Merece la pena, antes de tratar de la personalidad de su sucesor, referirse a la reacción de los distintos medios diplomáticos extranjeros en Madrid ante la desaparición de Jordana ${ }^{13}$. Al hacerlo es preciso partir de la base de que a estas alturas no existía en España una representación diplomática de verdadera importancia de los paises del Eje sino que estaba en manos de segundas figuras. Sin embargo el juicio del representante de la Francia de Vichy, un régimen "colaboracionista" no discrepó en nada esencial de lo señalado por los diplomáticos aliados: Jordana, que tenía más virtudes de las que revelaba su aparente modestia, había sido capaz de producir un giro de primera importancia en la politica exterior española. La opinión del embajador norteamericano se parecía mucho: al fallecido "lo que le faltaba de brillantez y audacia lo suplía con tenacidad" y su presencia en el Gobierno español habia sido "providencial" en el momento más grave del desembarco en el Norte de Africa. Pero los juicios más positivos fueron los que en aquel momento manifestaron los representantes de Gran Bretaña y Portugal lo que no sólo tiene que ver con las mejores relaciones que tuvo Jordana con estos dos países sino con su talante político y vital. Pereira, el portugués lo describió como un "viejo amigo" cuya "calma sonriente, buen sentido, honradez y

13 HOARE, "Embajador", 306-312, Hoare, 3 y 5-VIII-1944, FO 371/39.816 y 8-IX-1944, FO 371/36.977; “ABC", 8-VIII-1944; PIETRI, "Mes années", 85-86; HAYES, “Misión", 291-295; PTPIOS, IV , 594-607. 
dignidad" constituían una excepción en "un pais tan desigual, apasionado y caprichoso". El juicio de Hoare todavía fue más positivo. Era un «auténtico anglófilo" que desde hacía mucho tiempo le había expresado su seguridad en la victoria aliada. Trabajador («no vi nunca un hombre tan volcado al trabajo"), honesto y humanitario habia sido capaz de reorientar la política exterior española tras la "mala herencia" de Serrano. Como Hayes pensaba también Hoare que si Serrano hubiera sido ministro en el momento del desembarco en el Norte de Africa «el curso de nuestra fortuna hubiera chocado con muchos escollos". Le achacó debilidad y una incapacidad para imponerse a quienes en la Administración tendían a acomodarse a la germanofilia tradicional pero en el texto enviado a sus superiores dió la sensación de haberse arrepentido de la dureza de que había hecho gala en algunas de las negociaciones celebradas con el desaparecido. Lo curioso del caso es que una parte considerable de su opinión recibió publicidad en España lo que pudo dar en ésta la sensación de que la política exterior había sido neutral; por supuesto nada apareció de sus tensiones con Franco y menos aún de sus intentos de dimisión.

En cuanto a la figura del sustituto, José Félix de Lequerica, se puede decir que también mereció de los representantes diplomáticos en Madrid un juicio bastante homogéneo. Hubo, en primer lugar, una considerable sorpresa. Las personalidades de las que se habló para ocupar el cargo (Sangróniz, Aunós, Yanguas, Alba, Ventosa, Nicolás Franco...) antes de saber finalmente de quién se trataría obedecian a un perfil idéntico: eran, con la excepción del último, todos ellos monárquicos y moderados. Se trataba, en definitiva, de un género de ministro que podía pilotar una política exterior vinculada a la presumiblemente inmediata victoria de los aliados en Europa y también una paralela reconversión política del régimen. Pero esto último era de manera precisa lo que ni en forma remota quería Franco. En realidad en la lista citada habia personas que resultaban inimaginables para Franco porque habían suscrito la petición de restauración monárquica (Alba o Ventosa). Lequerica tenía tras de sí un pasado monárquico - y no tenía inconveniente en afirmar a principios de los cuarenta que esa era la única opción posible para España- pero como tantos otros de esta filiación (un Goicochea, por ejemplo) resultó, ante todo y sobre todo, un franquista.

Nacido en 1890 en una familia que, sin pertenecer a la capa superior de la oligarquía vasca, sin duda estaba integrada en ella, Lequerica se nos ofrece como un caso muy peculiar en la derecha española de su tiempo. Inteligente y culto, cáustico y cínico, era la antítesis misma de la imagen arquetípica del derechista español. Su formación británica, tuvo la peculiaridad de contribuir a dar fundamentación teórica a su autoritarismo 
que le llevó a las filas del maurismo al final de la monarquía parlamentaria, a la colaboración con la Dictadura de Primo de Rivera y al antirrepublicanismo en las páginas de la prensa durante los años treinta. No fue nunca, sin embargo, por edad y por espíritu aristocrático, falangista. La Falange le pareció siempre "una casa de locas»: lo más característico de su persona fue siempre el desenfado con el que se proclamaba adicto a la dictadura unipersonal de una persona a la que aduló sin tasa pero a la que su inteligencia debía apreciar bastante menos. Sus cartas a Franco resultan tan abrumadoras en elogios para el destinatario como en maledicencias para sus superiores jerárquicos. El Caudillo le usó en unos medios como los de negocios en Estados Unidos a los que no tenía acceso fácil, aunque debió temer también su mala intención. La anécdota de acuerdo con la cual se declaró "carguista" (no carlista) le describe a la perfección en su cinismo pero hay que leer sus despachos, bien escritos y demostrativos de cultura y don de gentes, para captar su verdadero carácter y su capacidad de acción en el terreno diplomático.

A lo largo de la segunda guerra mundial Lequerica había desempeñado un papel importante en la política exterior española. No cabe la menor duda de que había ejercido un protagonismo de primerísima importancia en el régimen de Vichy gracias a su inteligencia y a sus condiciones diplomáticas pero no es menos evidente que el papel de éste habia sido la mejor expresión del colaboracionismo con los alemanes; la mejor prueba de ello consiste en que cuando el embajador alemán en París, Abetz, acudía a Vichy el único embajador con el que se entrevistaba era él. Más que "anglófobo", como le juzgaba el embajador portugués, era, en realidad, galófobo y le hubiera gustado que, sin más, Francia hubiera aceptado su reducción a la condición de potencia de segundo orden y un predominio español en áreas de influencia hasta entonces común; también consideró muy despreciativamente a Portugal. En todo momento, había creído en la victoria del Eje, aunque estuviera, en realidad, mucho más cerca de los elementos de extrema derecha autoritaria que del fascismo. Por eso no puede extrañar que su nombramiento como ministro estuviera condenado a producir una pésima impresión en los aliados y presagiara conflictos. El mismo no podía ignorar que así fuera puesto que el camión que traía sus muebles a España desde Francia fue detenido y asaltado por el maquis del que formaban parte esos exiliados españoles que él había tratado de extraditar a España para que en ella sufrieran un destino lamentable. Para Hoare el nombramiento de Lequerica resultaba una prueba evidente de que Franco no tenía solución porque testimoniaba que estaba dispuesto a permanecer ante todo y apoyarse en la Falange. Con tono entre despreciativo y conmiserativo aseguró a sus superiores en Londres que España 
caminaba a toda velocidad hacia una nueva guerra civil. Pereira, el embajador portugués, escribió algo de lo que no hay ni puede haber prueba fehaciente pero que bien puede ser cierto. Franco no dudó nada a la hora de nombrarle y eso hace pensar que había pensado en él como sustituto de Jordana antes de la muerte de éste. Tanto esta posibilidad, que habria consistido, en definitiva, en utilizar una persona de trayectoria completamente contraria para realizar la política impuesta por los acontecimientos, - la indicada por el embajador francés, según el cual fue la mejor manera que tuvo Franco de librarse de una enojosa representación ante Vichy, habrian sido muy típicas de Franco. Pero hay que tener en cuenta también que la mentalidad siempre autocomplaciente de Franco podía ver en él no el ausente de España durante los años de la guerra mundial (que, por lo tanto, sabía poco de cómo se habían tomado las grandes decisiones) sino un personaje brillante que habia intervenido ya en el momento de lograrse el armisticio entre Alemania y Francia y ahora podía conseguir algo parecido respecto de Gran Bretaña y Alemania si fuera cierta la visión que tenía Franco de los acontecimientos.

Lo que resulta más evidente, de cualquier modo, es que había un rasgo fundamental en Lequerica que era la absoluta impudicia con la que podía pasar a llevar a cabo una política que nada tenía que ver con su pasado. El embajador portugués llegó a la conclusión de que no tendría el menor empacho en "se refaire une virginité" (rehacerse una virginidad) y propugnar un acercamiento a los norteamericanos; Pereira estaba convencido de que, como no padecia de "taras falangistas" a él le resultaría posible entenderse con él. Hoare empleó también el francés, pero con una cita literaria (nada menos que de Stendhal): "c'est un homme qui digere" (es un hombre que digiere). Quería decir que no tenía reparos ni en la adulación ni en asumir cualquier cambio de rumbo, incluso diciendo que España siempre actuó igual en la política exterior ante la guerra mundial; quizá fue esto lo que le llevó al embajador británico a ausentarse de España. Hayes, que describió su aspecto externo como el de un hombre de negocios norteamericano - hoy emplearíamos el término "ejecutivo"- llegó a la conclusión de "se ajustaría" a las circunstancias. Todos los términos venían a ser semejantes para perfilar, en definitiva, la imagen del nuevo ministro ${ }^{14}$. No sólo esta caracterización servía para él sino también para buena parte de sus colaboradores. El subsecretario que nombró, Cristóbal

14 La tesis de CAVA, "José Félix Lequerica: biografia politica y gestión diplomática", luego parcialmente publicada, es abundante en documentación aunque demasiado complaciente en la interpretación. 
del Castillo, había estado junto a él en su puesto diplomático anterior y tenía idéntica fama a la suya, es decir la de un antiguo colaboracionista con los alemanes que, por tanto, era mal recibido de entrada por los aliados, pero que, como buen diplomático que era, podía adaptarse a las nuevas circunstancias bélicas. Algo parecido podía decirse de Doussinague cuyo papel relevante, en especial de cara a El Pardo, y máxima adaptabilidad, siempre manifiestos, ahora quedaron ratificados y aún potenciados, tal y como indican los despachos de los diplomáticos extranjeros en Madrid.

Lequerica, como Jordana y a diferencia de Serrano, mantuvo permanentemente informado a Franco de la evolución de la política exterior: la documentación en la actualidad depositada en Presidencia de Gobierno de esta procedencia es, por consiguiente, muy abundante. Sin embargo da la sensación de que Franco haya tomado más iniciativas y sobre él haya recaído la mayor parte de las decisiones de política exterior, ahora que veía en peligro su propio régimen; en ello fue ayudado de manera muy inmediata por Carrero. Lequerica no llevó tan puntualmente como Jordana la tarea burocrática en su Ministerio y, sobre todo, no presentó propuestas o alternativas respecto de la tarea a llevar a cabo. Es muy posible que en alguna ocasión empleara su característica maledicencia para referirse al propio régimen porque ni Carrero ni Franco acabaron por fiarse de él. Pero ello no obsta para que el segundo cambiara su idea respecto de la utilidad de una persona como él para sus propósitos.

Este rápido recorrido sobre la significación de los cuatro ministros de Asuntos Exteriores que España tuvo durante la segunda guerra mundial permite, en primer lugar, comprobar la pluralidad de talantes vitales e ideológicos que se daba en el régimen de Franco. Sin embargo mucho más importante que eso es el hecho de que la influencia que desempeñaron los ministros en la evolución de la política exterior fue también muy distinta. En realidad desde el punto de vista de la actitud española ante el conflicto bien puede decirse que Beigbeder y Lequerica resultaron relativamente intrascendentes y que si en el momento en que fueron ministros hubiera habido otras personas en su lugar la diferencia no había sido tan grande.

Pero este no es el caso ni de Serrano ni de Jordana. Ambos tuvieron una política propia que resultó, además, antitética y que en gran medida era independiente de la voluntad de Franco. Por supuesto esto no quiere indicar que fuera contraria a lo que el Caudillo pensaba o deseaba sino que tuvo la suficiente virtualidad como para inducirle a un decantamiento o a un cambio gradual. Por supuesto sobre estos dos ministros pesaron de manera decisiva las limitaciones a que quedaba sometida la posición de 
un país como España y las circunstancias derivadas de la evolución de los acontecimientos. Sin embargo no cabe duda de que también modificaron con una actitud propia la posición española. Es, por tanto, muy posible que si ellos no hubieran ocupado su puesto la situación hubiera sido muy distinta. La mejor prueba de ello la tenemos con sólo imaginar que hubiera podido suceder si Serrano hubiera sido ministro en el momento del desembarco aliado en el Norte de Africa o si Jordana hubiera tenido que estar presente en las conversaciones de Hendaya. 